\title{
COMPORTAMENTO, ATITUDES E CONSCIÊNCIA AM- BIENTAL QUANTO AO DESCARTE DE TELEFONES CE- LULARES: UM ESTUDO QUANTITATIVO NA CIDADE DE SANTA MARIA, RIO GRANDE DO SUL
}

\author{
BEHAVIOR, ATTITUDES AND ENVIRONMENTAL AWARENESS \\ FOR THE DISPOSAL OF MOBILE PHONES: A QUANTITATIVE \\ STUDY IN THE CITY OF SANTA MARIA, RIO GRANDE DO SUL
}

Data de submissão: 13-09-2015 Aceite: 07-07-2016

Daniel Luís Arenhardt ${ }^{1}$ Luana Inês Damke ${ }^{2}$ Luis Adriano Rodrigues ${ }^{3}$ Rafael Augusto Dill ${ }^{4}$ Marcelo Trevisan ${ }^{5}$

\section{RESUMO}

Este trabalho teve como objetivo identificar o comportamento dos consumidores da cidade de Santa Maria, Rio Grande do Sul, quanto às atitudes e à disposição em pagar para a reciclagem de aparelhos celulares. A literatura sobre resíduos eletrônicos, descarte de aparelhos celulares e Política Nacional de Resíduos Sólidos (PNRS) foi revista no intuito de subsidiar as análises realizadas. De natureza descritiva e quantitativa, esta pesquisa foi desenvolvida por meio da aplicação de questionários a 430 consumidores do município, tendo por base o modelo utilizado por Yin, Gao e Xu (2014). Os resultados mostraram que 56,1\% dos respondentes substituem seus celulares, no máximo, a cada dois anos, que apenas 7\% devolvem os aparelhos descartados para serem reciclados e que 69,1\% não concordam em pagar uma parte dos custos envolvendo a reciclagem dos telefones. O estudo constatou, ainda, que a maioria dos participantes da amostra não possui conhecimento sobre a legislação acerca do tratamento de resíduos eletroeletrônicos. Como implicações práticas, os achados deste estudo evidenciam a necessidade de políticas públicas eficazes para que aparelhos celulares sejam descartados corretamente, bem como de ações que visem conscientizar a população sobre o impacto dos resíduos eletrônicos no meio ambiente e suas responsabilidades para minimizar esse problema.

Palavras-chave: Resíduos eletroeletrônicos; Descarte de celulares; Disposição em pagar pela reciclagem

1 Possui graduação em Administração de Empresas pela Universidade do Vale do Rio dos Sinos, UNISINOS, Especialização em Agronegócio Ênfase em Mercados pela Universidade Federal do Paraná, UFPR, mestrado em Administração pela Universidade Federal de Santa Maria, UFSM e doutorado em andamento em Administração pela Universidade Federal de Santa Maria, UFSM. Santa Maria. Rio Grande do Sul. Brasil. E-mail: daniel.arenhardt@ufsm.br

2 Possui graduação em Administração - Gestão e Negócios Agroindustriais pelo Instituto de Ensino Superior de Santo Ângelo, IESA, especialização em Administração Estratégica pelo Instituto de Ensino Superior de Santo Ângelo, IESA e mestrado em andamento em Administração pela Universidade Federal de Santa Maria, UFSM. Santa Maria. Rio Grande do Sul. Brasil. E-mail: luanadamke@hotmail.com

3 Possui graduação em Administração-Comércio Exterior pelo Instituto Cenecista de Ensino Superior de Santo Ângelo, IESA, graduação em andamento em Programa Especial de Graduação de Formação de Professores Para A Educação P pela Universidade Federal de Santa Maria, UFSM, especialização em Pós-graduação em Gestão Estratégica pelo Instituto Cenecista de Ensino Superior de Santo Ângelo, IESA e mestrado em andamento em Administração pela Universidade Federal de Santa Maria, UFSM. Santa Maria. Rio Grande do Sul. Brasil. E-mail: luisadriano@bol.com.br

4 Possui graduação em Administração de Empresas pela Universidade da Região da Campanha, URCAMP, especialização em Pós- Graduação em Gestão Empresarial pela Universidade da Região da Campanha - Alegrete, URCAMP e especialização em Gestão Pública pela Universidade Federal de Santa Maria, UFSM. Santa Maria. Rio Grande do Sul. Brasil. E-mail: kakadill@yahoo.com.br

5 Possui graduação em Administração pela Universidade Federal de Santa Maria, UFSM, mestrado em Administração pela Universidade Federal de Santa Catarina, UFSC e doutorado em Administração pela Universidade Federal do Rio Grande do Sul, UFRGS. Atualmente é pesquisador colaborador em grupo de pesquisa da Universidade Federal do Rio Grande do Sul, integrante de projeto de pesquisa da Universidade Federal do Rio Grande do Sul e professor adjunto da Universidade Federal de Santa Maria. Santa Maria. Rio Grande do Sul. Brasil. E-mail: marcelotrev@gmail.com 


\section{ABSTRACT}

This study aimed to identify the behavior of consumers of the city of Santa Maria, Rio Grande do Sul regarding the attitudes and willingness to pay for the mobile phones recycling. The literature on electronic waste, disposal of cell phones and National Solid Waste Policy (PNRS) has been revised in order to subsidize the analyzes. Descriptive and quantitative in nature, this research was developed through the application of questionnaires to 430 municipal consumers, based on the model used by Yin, Gao and Xu (2014). The results showed that 56.1\% of respondents replace their phones on at most every two years, only $7 \%$ return the discarded appliances to be recycled and $69.1 \%$ do not agree to pay part of the costs involving the recycling of phones. The study found also that most of the sample participants do not have knowledge of the law regarding the treatment of electronic waste. As practical implications, the findings of this study highlight the need for effective public policies so that cell phones are disposed of properly, as well as actions aimed at raise awareness about the impact of electronic waste on the environment and their responsibilities to minimize this problem.

Keywords: Electronic waste; Disposal of mobile phones; Willingness to pay for recycling

\section{INTRODUÇÃO}

É cada dia mais evidente a preocupação das nações em relação à geração de resíduos eletrônicos, seja nos países desenvolvidos, seja nos países em desenvolvimento. O rápido crescimento econômico e a melhoria da qualidade de vida das pessoas têm promovido o aumento do consumo de bens eletroeletrônicos, o que, consequentemente, tem gerado mais resíduos após o descarte desses produtos. De acordo com Tanskanen (2012), países da União Europeia já estão produzindo, em média, 17 quilos de lixo eletrônico per capita anualmente, enquanto países em desenvolvimento, como China e Índia, produzem aproximadamente um quilo. Nos Estados Unidos, conforme Milovantseva e Saphores (2013), o e-lixo representa a fração de maior crescimento entre os resíduos urbanos. Tais números tendem a aumentar ainda mais nos próximos anos.

A principal preocupação com o rápido crescimento dos resíduos eletrônicos ao redor do mundo refere-se ao fato de que os processos de reciclagem podem representar um risco ao meio ambiente se esses resíduos não forem tratados de forma adequada em seu estágio final de vida. Substâncias perigosas podem contaminar o ambiente ou causar risco à saúde e à segurança das pessoas no momento em que forem descartadas. Exemplos de destinação inadequada do lixo eletrônico são amplamente encontrados na literatura (LADOU; LOVEGROVE, 2008; LEONARD, 2010; LUNDGREN, 2012; SAPHORES; OGUNSEITAN; SHAPIRO, 2012; SOO; DOOLAN, 2014), embora se percebam uma tendência de remoção de alguns materiais potencialmente perigosos nos produtos fabricados por parte da indústria de eletrônicos, minimizando o risco de contaminação (TANSKANEN, 2012), ou até mesmo incentivos para que empresas projetem e fabriquem produtos menos tóxicos e, com isso, menos danosos ao meio ambiente (RENNER, 2004). As empresas também devem se preocupar com a repercussão de suas ações na comunidade global, pois, ao disponibilizar produtos com ciclos de vida cada vez mais curtos, usando materiais e processos perigosos e gerando resíduos tanto durante a fabricação quanto no fim da vida, fabricantes de Equipamentos Elétricos e Eletrônicos (EEE) tornaram-se alvo de grupos ambientalistas como o Greenpeace, que destacam as deficiências de muitas grandes empresas de eletrônicos internacionais (GOOSEY, 2009).

Especificamente sobre o descarte de aparelhos celulares, no Brasil, não existem estatísticas oficiais. Contudo, segundo dados da Teleco (2015), em maio de 2015 , havia no país 284,2 milhões de celulares em circulação, o que representa uma densidade de 139,2 aparelhos por 100 habitantes - pressupondo uma grande quantidade de descarte de aparelhos por ano. De acordo 
com Xavier e Carvalho (2014), a União Europeia motivou o comprometimento por parte de diversos países, e, na América Latina, o Brasil ganhou papel de destaque a partir da elaboração das políticas estaduais e da Política Nacional de Resíduos Sólidos (PNRS), que trata sobre a correta destinação de resíduos eletroeletrônicos. Para as autoras, o Brasil destaca-se entre os países latino-americanos pela profundidade de sua abordagem nos instrumentos legais acerca da temática e ainda pela prioridade dada, no âmbito da inclusão social, aos catadores de materiais recicláveis.

Inserido nesse contexto, o presente artigo tem como objetivo identificar o comportamento dos consumidores da cidade de Santa Maria, Rio Grande do Sul, quanto às atitudes de descarte e à disposição para a reciclagem de aparelhos celulares. Nesse sentido, por meio da aplicação de questionários, buscou-se verificar a percepção e o conhecimento sobre a reciclagem, bem como a disposição em pagar para que esse processo ocorra, de uma amostra populacional do município.

Considerando a emergência do tema e as graves consequências que o descarte inadequado de produtos eletroeletrônicos pode ocasionar ao planeta e à sociedade, o presente estudo justifica-se porque permite averiguar as atitudes e o conhecimento dos consumidores sobre o assunto, partindo de uma realidade local, mas que traz contribuições para o aprimoramento de toda a cadeia da coleta de aparelhos celulares do país. Como contribuição teórica, toda pesquisa empírica possibilita mapear, refinar, relacionar e/ou delinear padrões que pressupõem causalidade entre determinado grupo de fatores (WHETTEN, 2003). No caso em questão, pesquisar sobre o comportamento, as atitudes e a disposição quanto à reciclagem de telefones celulares significa avançar na descrição e na explicação do tema, omitindo-se de tratar o problema do descarte apenas por meio de exposições indutivas e generalizáveis.

Para atender os objetivos propostos, este trabalho está organizado da seguinte forma: primeiramente, apresenta-se uma breve revisão da literatura sobre resíduos eletrônicos e descarte de aparelhos e descrevem-se os principais resultados de pesquisas no mundo que abordam a disposição dos consumidores em reciclarem seus aparelhos celulares descartados; na sequência, apresentam-se a metodologia utilizada no trabalho e a justificativa para sua escolha; após, descrevem-se os resultados encontrados com a aplicação dos questionários; e, por fim, são tecidas algumas considerações finais e sugestões para pesquisas futuras.

\section{REFERENCIAL TEÓRICO}

O referencial teórico está dividido em três seções: a primeira delas aborda aspectos relacionados a resíduos eletrônicos; a segunda trata sobre o descarte dos aparelhos celulares; e a terceira apresenta os resultados de pesquisas realizadas sobre o descarte e a disposição dos consumidores em pagar pela reciclagem.

\subsection{Resíduo eletrônico}

Até recentemente, boa parte dos resíduos nocivos gerados a partir de produtos eletrônicos, entre eles computadores antigos, telefones celulares e televisores de nações mais ricas, era enviada para países em desenvolvimento, como China, Paquistão e Bangladesh, onde o trabalho é mais barato e as leis ambientais são mais negligentes (GROSSMAN, 2006). Apesar de restrições impostas pela Convenção da Basileia das Nações Unidas terem desacelerado a exportação de lixo eletrônico, que passou a ser acompanhada mais de perto e imposta a maiores restrições (XAVIER; CARVALHO, 2014), esse fenômeno continua a ocorrer em uma escala gigantesca 
e destrutiva (BOSTMAN; ROGERS, 2010). De acordo com Leonard (2010), apenas 12,5\% do lixo eletrônico produzido nos Estados Unidos é recolhido para ser reciclado. Dentre esse montante, aproximadamente $80 \%$ são encaminhados para descarte em países em desenvolvimento, existindo, conforme Luther (2010), pouca informação disponível sobre a quantidade total de produtos eletrônicos exportados para países em desenvolvimento para a legítima reutilização.

Nesse contexto, eletroeletrônicos e outros aparelhos são, muitas vezes, considerados "desatualizados" após um período relativamente curto. Seus proprietários são incentivados a trocar tais produtos para aproveitar promoções de outros aparelhos com melhor qualidade (MACKENZIE; COOPER; GARNETT, 2010). Como resultado, grandes quantidades de resíduos eletroeletrônicos são geradas diariamente.

A indústria eletrônica fornece, assim, dispositivos que se tornaram essenciais para o modo de vida moderno, representando, ao mesmo tempo, uma área onde as oportunidades de operar de maneira sustentável ainda não foram exploradas. Na verdade, muitos EEE são tipicamente caracterizados por determinado número de fatores, incluindo a melhoria do desempenho e o custo reduzido a cada nova geração de produtos, o que acaba encorajando comportamentos insustentáveis (GOOSEY, 2009). Como descrevem Bostman e Rogers (2010), hoje, somos uma sociedade viciada em "hábitos de descarte", e muitos de nós estamos anestesiados em relação às suas consequências.

Para Milovantseva e Saphores (2013), algumas medidas simples poderiam ser adotadas para minimizar os impactos ambientais e resolver os desafios da saúde pública envolvendo o descarte de lixo eletrônico, como aumentar os percentuais de reciclagem e incentivar a indústria para que desenvolvam produtos eletrônicos "verdes", evitando assim materiais potencialmente tóxicos. Todavia, conforme descrevem os autores, embora existam esforços por parte de agentes reguladores (na Europa, nos Estados Unidos e na China, por exemplo), bem como de órgãos de defesa do consumidor, que pressionaram a criação de regulamentos proibindo alguns materiais tóxicos (como o chumbo) na fabricação de produtos em determinados países, ainda há muitos produtos eletrônicos com materiais potencialmente perigosos (MILOVANTSEVA; SAPHORES, 2013).

No Brasil, de acordo com Xavier e Carvalho (2014), a gestão de resíduos tem sido motivada, principalmente, por exigências legais, embora aspectos de ordem social, econômica e ambiental também desencadeiam ações e favorecem as políticas públicas nesse segmento. Por vezes considerado um problema de ordem social e/ou de ordem econômica, a gestão de resíduos suscita amplas discussões e embates em diferentes esferas do poder.

\subsection{O descarte de aparelhos celulares}

De acordo com a International Telecomunication Union (ITU, 2015), em 2001 havia, em média, 15,5 aparelhos celulares habilitados para cada 100 habitantes. Em 2014, eram 96,1 telefones por 100 habitantes, totalizando aproximadamente sete bilhões de aparelhos em atividade. Assim, em 2014, nos países desenvolvidos, existiam 119,6 aparelhos para cada 100 habitantes, enquanto que, nos países em desenvolvimento, esse número chegou a 91,1 aparelhos (ITU, 2015). Para Diouf, Pose e Osei (2015), a vida útil de um telefone celular é curta principalmente pela rápida evolução da tecnologia apoiada por um marketing agressivo. Seu ciclo de vida, conforme Soo e Doolan (2014), é um dos mais reduzidos entre os produtos eletrônicos, conduzindo a um aumento do lixo eletrônico.

Conforme apresenta Huisman (2004), os telefones celulares são constituídos predominantemente de plástico, cobre, vidro e ferro. Todavia, também contêm substâncias perigosas, como níquel, cromo e chumbo - ainda que em menores quantidades. De acordo com Askerzai (2010), celulares descartados em aterros podem descarregar produtos químicos perigosos e tóxicos, como 
antimônio, arsênio, berílio, cobre, chumbo, níquel, mercúrio, manganês, lítio, zinco e cádmio. Mesmo em pequenas quantidades, essas substâncias químicas podem causar contaminação ambiental, afetando os cursos d' água, a vida selvagem e a saúde humana. Para Renner (2004), tal como os computadores, os telefones celulares são produtos de vida curta que apresentam uma ameaça mais clara para a saúde humana e ambiental quando são fabricados ou destruídos, porque contêm substâncias tóxicas em seus chips e semicondutores. A análise do ciclo de vida identifica a placa do telefone, que contém chip de circuito e display de cristal líquido, e as baterias como os maiores perigos, seguidos pelo invólucro de plástico, que é difícil de reciclar (RENNER, 2004).

$\mathrm{O}$ descarte de telefones celulares coloca em competição os setores formais e informais da reciclagem, principalmente nos países em desenvolvimento, onde a baixa disposição em pagar pelo tratamento dos resíduos inibe o desenvolvimento de cadeias produtivas estruturadas para a realização da atividade. Em países desenvolvidos, conforme descrevem Soo e Doolan (2014), sistemas de recolhimento são incentivados por meio de programas de governo e por meio da responsabilidade compartilhada do ciclo de vida do produto, criando maior colaboração entre fabricante e consumidores e aumentando as taxas de devolução e coleta dos aparelhos descartados.

Conforme $\mathrm{Hu}$ (2012), os processos de reciclagem poderiam utilizar os materiais recolhidos em novos produtos, a fim de reduzir ou evitar que materiais ou energia fossem desperdiçados. Um exemplo de reciclagem é a reutilização do chip de memória, que poderia ser usado para substituir um chip de tamanho pequeno em outro dispositivo. $O$ autor evidencia, ainda, a possibilidade de reutilização do próprio aparelho. Em vez da reciclagem dos telefones, eles poderiam ser utilizados por outras pessoas ou para outros fins. A reutilização é um meio de usar um produto mais de uma vez para a mesma função ou em funções diferentes. Como exemplo, Hu (2012) descreve que os telefones celulares simples podem não atender mais às necessidades das pessoas que $o$ adquiriram, mas poderiam atender a outros usuários, em áreas menos desenvolvidas, que ficariam felizes em possuir um telefone, mesmo que este apresentasse funções mais simples. Para Geyer e Blass (2010), os telefones celulares são um dos poucos produtos eletrônicos, se não o único, que também possuem um mercado de reutilização próspero - maior, talvez, do que o próprio mercado de reciclagem.

\subsection{Pesquisas sobre o descarte e a disposição para a reciclagem de aparelhos celulares}

Durante os últimos anos, vários estudos foram realizados sobre o descarte e a reciclagem de aparelhos celulares em diversos países. Nnorom, Ohakwe e Osibanjo (2009) estudaram o comportamento do consumidor em duas cidades da Nigéria, aplicando 1.000 questionários. Seus resultados evidenciaram que $51 \%$ dos entrevistados estavam dispostos a pagar um valor adicional de $20 \%$ sobre o preço dos aparelhos convencionais para ter um celular fabricado ecologicamente.

Jang e Kim (2010) desenvolveram um estudo na Coreia com 1.090 consumidores e constataram que o tempo médio de vida dos aparelhos celulares da população daquele país é de 2,4 anos. Os resultados também mostraram que $42,2 \%$ dos aparelhos descartados foram devolvidos pelos consumidores para reciclagem, enquanto que aproximadamente $40 \%$ dos entrevistados disseram guardar seus aparelhos em casa após o fim de sua vida útil.

Giaretta et al. (2010) desenvolveram uma pesquisa sobre o descarte pós-consumo de aparelhos celulares com alunos da Universidade de São Paulo (USP), aplicando 223 questionários. Quanto à destinação dos aparelhos descartados, $42,5 \%$ dos entrevistados guardaram seus celulares, $22,4 \%$ doaram o telefone e apenas $5,6 \%$ o devolveram para a operadora ou o fabricante. 
Li et al. (2012) aplicaram um questionário a 1.011 estudantes universitários chineses, para verificar o comportamento de eliminação de telefones celulares e a disposição em pagar pela reciclagem dos aparelhos. Seus resultados apontaram que $38 \%$ dos entrevistados substituem seus aparelhos em média a cada dois ou três anos de uso, sendo a quebra do telefone a razão mais comum $(65,8 \%)$ para a troca. A pesquisa também identificou que $64 \%$ dos estudantes guardam seus aparelhos descartados em casa.

Cruz-Sotelo et al. (2013) estudaram os hábitos de consumo e de gestão de resíduos celulares de uma amostra de estudantes universitários da Espanha e do México. Foram aplicados 533 questionários, e os autores verificaram que 52\% dos entrevistados espanhóis e $25 \%$ dos mexicanos armazenaram em casa seus celulares em desuso, enquanto que $19 \%$ dos participantes espanhóis e 33\% dos mexicanos doaram os aparelhos para parentes ou amigos após nova aquisição. Quanto ao tempo de vida útil do celular, tanto os estudantes espanhóis (66\%) quanto os estudantes mexicanos (63\%) declararam que o tempo médio dos aparelhos era de 18 meses.

Koga et al. (2014) aplicaram uma pesquisa on-line com 410 consumidores do estado de São Paulo e constataram que $27 \%$ e $25 \%$, respectivamente, dos entrevistados descartaram seus aparelhos celulares por desatualização tecnológica e por quebra. Em relação à periodicidade de substituição dos aparelhos, os resultados apontaram que $62 \%$ trocam a cada dois anos e que $38 \%$ realizam a troca a cada três anos ou mais. A pesquisa também identificou que $46 \%$ dos respondentes guardaram seus celulares antigos em casa, $34 \%$ doaram para alguém e apenas $7 \%$ destinaram o aparelho para reciclagem.

Yin, Gao e Xu (2014) investigaram o comportamento em relação à reciclagem de celulares em escala nacional na China, aplicando questionários a 1.035 consumidores nas quatro macrorregiões do país. Os resultados mostraram que 31,9\% dos participantes trocam de aparelho, em média, a cada três anos e que, para $43,8 \%$, o principal motivo da troca consiste no fato de os celulares estarem danificados. Quanto à destinação dos aparelhos descartados, $47,1 \%$ dos respondentes disseram que guardam os celulares em casa e $28,1 \%$ declararam ter entregado o aparelho para reciclagem. Como principal motivo declarado pelos participantes para não destinarem seus aparelhos para reciclagem, $45,9 \%$ declararam que não sabem para onde enviar os telefones. A pesquisa também evidenciou que $52,1 \%$ dos participantes não concordam com o pagamento de qualquer taxa para colaborar com os custos de reciclagem dos celulares.

\section{METODOLOGIA}

Este trabalho se caracteriza como uma pesquisa quantitativa, de natureza descritiva. De acordo com Churchill e lacobussi (2009), o método descritivo é utilizado quando o objetivo consiste em descrever as características de certos grupos, estimar a proporção de pessoas que se comportam de determinada maneira ou fazer previsões específicas. Na sequência, são descritos o modelo adotado, o tamanho e a distribuição da amostra da pesquisa e o instrumento utilizado para a coleta dos dados.

Para fins de aplicação desta pesquisa, foi utilizado como base o modelo conceitual de Yin, Gao e Xu (2014), que pesquisaram o comportamento para a reciclagem de uma amostra populacional da China, por meio da aplicação de 1.035 questionários a consumidores residentes em quatro grandes províncias daquele país. A Tabela 1, exposta a seguir, apresenta os construtos e as variáveis utilizadas pelos autores e empregadas também neste estudo. 
Tabela 1 - Construtos e variáveis do modelo utilizado na pesquisa

\begin{tabular}{|c|c|}
\hline Construtos & Variáveis \\
\hline $\begin{array}{l}\text { Comporta- } \\
\text { mento do } \\
\text { consumidor }\end{array}$ & $\begin{array}{l}\text { 1. Tempo médio de vida do celular } \\
\text { 2. Razão da substituição do celular } \\
\text { 3. Tratamento dado ao celular descartado } \\
\text { 4. Disposição para reciclar o celular descartado } \\
\text { 5. Opinião sobre a baixa taxa de reciclagem de celulares no país } \\
\text { 6. Preferência por formas de coleta ou descarte de aparelhos para reciclagem }\end{array}$ \\
\hline $\begin{array}{c}\text { Consciência } \\
\text { ambiental }\end{array}$ & $\begin{array}{l}\text { 1. Conhecimento de programas de reciclagem promovidos por empresas de telefonia móvel } \\
\text { 2. Consciência acerca das substâncias tóxicas (chumbo, mercúrio e arsênio) dos celulares } \\
\text { 3. Consciência acerca das substâncias preciosas (ouro, prata e paládio) dos celulares } \\
\text { 4. Consciência acerca da responsabilidade do fabricante sobre a reciclagem dos celulares } \\
\text { 5. Consciência sobre a legislação ambiental - especificamente sobre reciclagem }\end{array}$ \\
\hline $\begin{array}{l}\text { Disposição } \\
\text { em pagar } \\
\text { pela recicla- } \\
\text { gem }\end{array}$ & $\begin{array}{l}\text { 1. Opinião sobre quem deve assumir a responsabilidade pela reciclagem de celulares } \\
\text { 2. Opinião sobre o pagamento pelo consumidor de taxas para reciclagem de celulares } \\
\text { 3. Disposição em pagar um percentual dos custos para reciclagem de celulares }\end{array}$ \\
\hline
\end{tabular}
Fonte: adaptado de Yin, Gao e Xu (2014).

Além das variáveis propostas por Yin, Gao e Xu (2014), este artigo também questionou os participantes sobre o significado do aparelho. Para Douglas e Isherwood (1996), o consumo de bens e serviços pode revelar-se como gerador de identidades e de pertencimento a grupos sociais. Por meio do consumo, as pessoas estabelecem suas identidades, promovem inclusão e exclusão social e diferenciam-se umas das outras. $O$ objetivo foi verificar se esse comportamento também é percebido entre os respondentes desta pesquisa em relação ao aparelho celular.

Considerando o objetivo proposto (identificar o comportamento dos consumidores da cidade de Santa Maria), o cálculo para determinar o tamanho da amostra foi realizado com base na estimativa da proporção populacional do referido município. Amparado no cálculo da amostra de populações infinitas - comumente utilizado para calcular amostras quando não se conhece o tamanho da população ou quando se trata de populações acima de 100.000 pessoas -, com uma margem de erro de $5 \%$ e um nível de confiança de $95 \%$, chegou-se ao número mínimo de 384 questionários a serem aplicados para manter a pesquisa dentro dos níveis de erro definidos.

A escolha do município de Santa Maria deveu-se, além da facilidade de aplicação dos questionários por parte dos autores, à diversidade cultural e socioeconômica desse município de médio porte situado no sul do Brasil - atributos que o fazem importante no cenário tanto estadual quanto nacional. Santa Maria é a quinta cidade mais populosa do Rio Grande do Sul e figura entre as 100 maiores do país, com estimativa de 276.108 habitantes, segundo levantamento realizado pelo Instituo Brasileiro de Geografia e Estatística (IBGE) em 2015. Seu Produto Interno Bruto (PIB) a preços correntes ( $\mathrm{R}$ 5.701.470) situa-se entre os 150 maiores do Brasil, e seu Índice de Desenvolvimento Humano Municipal (IDHM), classificado como "alto", também se encontra entre os 100 melhores do país (0,784), superando capitais como Recife, Aracaju e Salvador (IBGE, 2015). Todas essas características levam os autores a acreditarem que a escolha do município de Santa Maria representa adequadamente o comportamento e as atitudes de uma parcela significativa da população brasileira quanto ao tema que é objeto de análise deste estudo.

Ainda assim, como forma de melhor representar a população escolhida, definiu-se como critério de estratificação da amostra, para aplicação dos questionários, o nível de escolaridade dos residentes no município, conforme dados divulgados pelo IBGE e apresentados na Tabela 2. 
Tabela 2 - Proporção do nível de instrução das pessoas com dez anos ou mais de idade

\begin{tabular}{ccc} 
Escolaridade - população de Santa Maria & Percentual & $\begin{array}{c}\text { N.o mínimo de questio- } \\
\text { nários }\end{array}$ \\
Sem instrução e ensino fundamental incompleto & 37,50 & 144 \\
Ensino fundamental completo e médio incompleto & 18,41 & 71 \\
Ensino médio completo e superior incompleto & 29,67 & 114 \\
Ensino superior completo & 14,42 & 55 \\
\hline Total & $\mathbf{1 0 0 , 0 0}$ & $\mathbf{3 8 4}$ \\
\hline
\end{tabular}

Fonte: Censo Demográfico 2010: Resultados da Amostra - Características da População.

Dessa forma, o número mínimo de questionários coletados em cada nível de escolaridade respeitou o percentual estabelecido na Tabela 2. Ao final, foram aplicados 430 inquéritos, conforme apresenta a Tabela 3.

Os dados foram coletados por meio de um questionário composto de 17 questões de múltipla escolha (além das questões referentes aos dados pessoais), divididas em três seções: percepção sobre o aparelho celular e sobre o seu descarte; conhecimento ambiental dos consumidores; e disposição em pagar pela reciclagem. Considerando que uma parte da amostra possuía baixo nível de escolaridade - conforme estratificação na Tabela 3 -, optou-se pela utilização apenas de uma escala categórica ou não métrica (HAIR, et al., 2007), uma vez que escalas de intensidade apresentando opções como "concordo totalmente" e "concordo" poderiam causar confusão no momento da escolha da melhor resposta. Nesse sentido, Hair et al. (2007) argumentam que, nesses casos, a análise estatística dos dados tem pouca sofisticação.

A aplicação ocorreu entre os meses de maio e junho de 2015 em diferentes pontos e locais de cidade, incluindo universidades, calçadão, feiras, escolas de Educação de Jovens e Adultos (EJA), centro popular de compras e paradas de ônibus. No intuito de maximizar a confiabilidade das respostas, os questionários foram aplicados, predominantemente de forma oral, pelos autores do estudo, ao mesmo tempo que cada questão e cada possibilidade de resposta eram esclarecidas aos participantes. Os dados coletados foram analisados com a ajuda do software estatístico SPSS $^{\circ}$ e da planilha eletrônica Microsoft ${ }^{\circ}$ Excel.

\section{RESULTADOS}

Nesta seção, são apresentados os dados demográficos da amostra participante do estudo, a percepção sobre o aparelho celular e seu descarte, o conhecimento ambiental dos consumidores e a disposição em pagar pela reciclagem dos aparelhos celulares e dos resíduos resultantes.

\subsection{Dados demográficos}

A amostra participante do estudo foi composta em sua maioria $(57,2 \%)$ de homens. Quanto à idade, 60,5\% possuíam 34 anos ou menos no momento da pesquisa e 57,2\% dos entrevistados não possuíam o ensino médio completo. A Tabela 3, exposta a seguir, apresenta a estratificação das informações pessoais mais detalhadamente. 
Tabela 3 - Número e proporção (\%) relativos à idade e escolaridade dos participantes

\begin{tabular}{cccccc} 
Faixa etária & N. & $(\%)$ & Nível de Escolaridade & N.o & (\%) \\
$<=24$ & 178 & 41,4 & Sem Inst./Fund. Inc. & 150 & 34,9 \\
25 a 34 & 82 & 19,1 & Fund. Comp./Méd. Inc. & 96 & 22,3 \\
35 a 44 & 67 & 15,6 & Méd. Comp./Sup. Inc. & 126 & 29,3 \\
45 a 54 & 65 & 15,1 & Sup. Comp. & 58 & 13,5 \\
$>54$ & 38 & 8,8 & & & \\
\hline
\end{tabular}

Salienta-se que o maior número de respondentes se situou na faixa sem instrução ou ensino fundamental incompleto, devido à escolha dos autores em representar percentualmente a amostra de acordo com o nível de escolaridade do município de Santa Maria, conforme dados do IBGE (2015).

\subsection{Percepção sobre o aparelho celular e seu descarte}

A primeira pergunta do questionário buscou verificar com que frequência os usuários substituem seus telefones celulares. Conforme apresentado na Tabela 4, os resultados apontaram que $31,9 \%$ dos participantes substituem seus aparelhos, em média, a cada dois anos e que $24,2 \%$ realizam tal substituição a cada ano. Outros $17,9 \%$ dos respondentes assinalaram fazem essa troca a cada três anos, e apenas 7,4\% permanecem com o mesmo aparelho por mais de cinco anos. Percentuais semelhantes também foram encontrados em outros estudos. No trabalho de Yin, Gao e Xu (2014), 32\% dos participantes disseram trocar de celular a cada dois anos; e, no estudo de Li et al. (2012), 38\% dos respondentes substituem o telefone celular a cada dois ou três anos. Conforme descrevem Ongondo e Williams (2011), em decorrência do rápido avanço tecnológico nos produtos de telefonia e do consequente aumento de suas funcionalidades, que passaram a incluir câmeras fotográficas e players de música, por exemplo, tornou-se perceptível a redução do ciclo de vida dos aparelhos - que são vistos como obsoletos pelos usuários dentro de pouco mais de um ano.

Tabela 4 - Número e proporção (\%) relativos à frequência de substituição do celular

\begin{tabular}{ccc} 
Com quê frequência substitui o celular & N.o de respostas & \% de respostas \\
A cada dois anos & 137 & 31,9 \\
A cada ano & 104 & 24,2 \\
A cada três anos & 77 & 17,9 \\
A cada quatro anos & 46 & 10,7 \\
A cada cinco anos & 34 & 7,9 \\
Mais de cinco anos & 32 & 7,4 \\
\hline Total & $\mathbf{4 3 0}$ & $\mathbf{1 0 0 , 0}$ \\
\hline
\end{tabular}

Quanto ao principal motivo pelo qual os participantes substituem o aparelho celular, mais da metade $(53,5 \%)$ alegou o estrago do telefone antigo, $22,8 \%$ indicaram as funções desatualizadas e 15,3\% sinalizaram o estilo fora de moda. A pesquisa de Cruz-Sotelo et al. (2013) com estudantes universitários da Espanha e do México também identificou a quebra e/ou o estrago como o principal motivo para a troca do telefone, sendo apontado por $37 \%$ dos espanhóis e $46 \%$ dos mexicanos. No estudo de Koga et al. (2014), realizado com consumidores do estado de São Paulo, o principal motivo apontado pelos respondentes foi o estilo desatualizado (27\%), seguido da quebra do aparelho (25\%). 
Também foi questionado o significado do aparelho para os respondentes. Para $88,8 \%$ dos entrevistados, o telefone é unicamente funcional (fazer e receber ligações, enviar mensagens, conectar-se à internet etc.). Apenas 2,1\% da amostra disse ser o telefone um objeto de status e prestígio e outros 2,1\% afirmaram que tal objeto os faz se sentirem na moda. Ressaltase que o elevado número de respostas na primeira opção (unicamente funcional) pode ter sido influenciado pelo fato de que a grande maioria dos questionários foi aplicada oralmente pelos autores da pesquisa, inibindo os respondentes de escolherem as outras possibilidades.

No que se refere ao destino dado aos aparelhos descartados, a pesquisa identificou que $48,6 \%$ dos respondentes guardam os telefones em casa, enquanto que $25,3 \%$ doaram ou venderam o antigo aparelho para algum parente ou amigo. Apenas $7 \%$ dos respondentes devolveram o celular à operadora ou ao fabricante para que fosse reciclado. Resultados semelhantes também foram encontrados por Koga et al. (2014).

Quando questionados sobre o motivo pelo qual não entregaram o aparelho para ser reciclado, $40 \%$ não sabiam para onde enviar o telefone descartado e 31,2\% preferiram doar o telefone a familiares ou amigos do que entregá-lo em algum ponto de coleta e não receber nada em troca. A Tabela 5, exposta a seguir, discrimina o número de respostas a essa pergunta e o percentual obtido em cada uma das opções. Saphores, Ogunseitan e Shapiro (2012) evidenciaram em seu estudo com famílias norte-americanas que saber onde os pontos de coleta estão localizados aumenta a disposição das pessoas em destinarem os aparelhos eletrônicos para a reciclagem. Giaretta et al. (2010), por sua vez, descrevem a necessidade, no Brasil, de intensificar a divulgação e a atuação das operadoras por meio de campanhas mais objetivas e efetivas, uma vez que, conforme verificaram, embora as operadoras mantenham em seus websites links que esclarecem sobre a coleta e a reciclagem, há pouca divulgação dessas campanhas, que se mostram uma estratégia frágil e de pouco alcance.

Tabela 5 - Número e proporção (\%) relativos ao destino dado ao aparelho e motivo de não o ter destinado à reciclagem

\begin{tabular}{|c|c|c|c|c|c|}
\hline $\begin{array}{l}\text { Destino dado ao apare- } \\
\text { Iho descartado }\end{array}$ & $\begin{array}{l}\text { N.o de } \\
\text { respostas }\end{array}$ & $\begin{array}{l}\text { \% de res- } \\
\text { postas }\end{array}$ & $\begin{array}{l}\text { Qual o motivo de não } \\
\text { devolver o celular para } \\
\text { reciclagem? }\end{array}$ & $\begin{array}{l}\text { N.o de res- } \\
\text { postas }\end{array}$ & $\begin{array}{l}\text { \% de res- } \\
\text { postas }\end{array}$ \\
\hline Guardou em casa & 209 & 48,6 & Não sabia onde entregar & 163 & 40,0 \\
\hline $\begin{array}{l}\text { Doou ou vendeu a um pa- } \\
\text { rente ou amigo }\end{array}$ & 109 & 25,3 & $\begin{array}{c}\text { Preferiu doar o telefone a } \\
\text { algum familiar }\end{array}$ & 127 & 31,2 \\
\hline $\begin{array}{c}\text { Negociou na compra de } \\
\text { um novo aparelho }\end{array}$ & 65 & 15,1 & Outros & 70 & 16,3 \\
\hline $\begin{array}{c}\text { Devolveu à operadora ou } \\
\text { ao fabricante para reci- } \\
\text { clagem }\end{array}$ & 30 & 7,0 & $\begin{array}{c}\text { Utiliza o antigo aparelho } \\
\text { para armazenar dados }\end{array}$ & 24 & 5,9 \\
\hline $\begin{array}{c}\text { Jogou fora como lixo co- } \\
\text { mum }\end{array}$ & 13 & 3,0 & \multirow[t]{2}{*}{$\begin{array}{c}\text { Receia a divulgação de da- } \\
\text { dos pessoais }\end{array}$} & \multirow{2}{*}{23} & \multirow{2}{*}{5,7} \\
\hline $\begin{array}{c}\text { Vendeu no comércio in- } \\
\text { formal }\end{array}$ & 4 & 0,9 & & & \\
\hline Total & 430 & 100,0 & & 407 & 100,0 \\
\hline
\end{tabular}

A percepção dos participantes quanto ao pouco interesse pela reciclagem dos aparelhos celulares no Brasil também foi questionada. Na opinião de $57,9 \%$ dos respondentes, isso ocorre porque há pouca divulgação para que as pessoas reciclem. Para $24,2 \%$ dos participantes, tal fator se deve à falta de consciência das pessoas. Outros $8,4 \%$ disseram que as pessoas não se interessam em entregar os celulares descartados para reciclagem porque o governo não as obriga. Conforme Geyer e Blass (2010), algumas atividades de reutilização e de reciclagem são voluntá- 
rias e motivadas por aspectos ambientais, mas a maioria das iniciativas ocorre pela economia de mercado ou pela exigência de alguma legislação.

\subsection{Conhecimento ambiental dos consumidores}

Na segunda parte do inquérito, foram propostas questões que avaliaram o nível de conhecimento dos participantes em relação aos componentes presentes nos aparelhos celulares e em relação à legislação que versa sobre a correta destinação e o descarte de resíduos eletroeletrônicos, especificamente a PNRS (Lei n.o 12.305/10). Nesse sentido, 342 respondentes (79,5\%) disseram ter conhecimento da existência de substâncias tóxicas (como chumbo, mercúrio e arsênio) nos aparelhos celulares. Em relação aos metais preciosos constantes nos aparelhos (como ouro, prata e paládio), apenas 131 respondentes $(30,5 \%)$ disseram saber de sua existência, em contraposição a 299 (69,5\%) que não sabiam.

Quando os participantes foram questionados sobre a existência de uma legislação que trata da reciclagem de aparelhos celulares, apenas 103 respondentes (26,3\%) disseram conhecer tal lei, enquanto que 317 (73,7\%) desconheciam essa legislação. Sobre a responsabilidade compartilhada (incluindo os consumidores) pela correta destinação de resíduos eletrônicos e sua reciclagem, 110 respondentes $(25,6 \%)$ afirmaram saber que também fazem parte dessa cadeia do ciclo de vida do produto, enquanto 319 participantes $(74,2 \%)$ não sabiam que a responsabilidade é de todos os envolvidos, inclusive dos consumidores.

Ainda em relação à legislação, foi questionado aos participantes se tinham conhecimento de que é obrigação de quem fabrica e vende os telefones celulares receber de volta os aparelhos descartados para reciclagem - em alusão ao que estabelece o artigo 33, item VI, da PNRS. Como resposta, apenas 89 entrevistados $(20,7 \%)$ sabiam dessa obrigatoriedade, enquanto $340(79,1 \%)$ a desconheciam. Essa falta de informação e de conhecimento pode ser atribuída, em grande parte, aos fabricantes e às operadoras de telefonia móvel que operam no país. Em levantamento realizado por Silveira e Chang (2010), ficou evidenciado que, enquanto nos Estados Unidos os programas de reciclagem dos fabricantes normalmente oferecem etiquetas de transporte pré-pago on-line e incentivos para que os usuários devolvam seus aparelhos no momento de uma nova compra, inclusive com benefícios financeiros, no Brasil, os fabricantes não oferecem as mesmas alternativas para a reciclagem dos aparelhos. Algumas operadoras, conforme os autores, sequer oferecem qualquer oportunidade para a reciclagem. O Gráfico 1, exposto a seguir, traz as questões e o percentual das respostas dos participantes a esse respeito. 


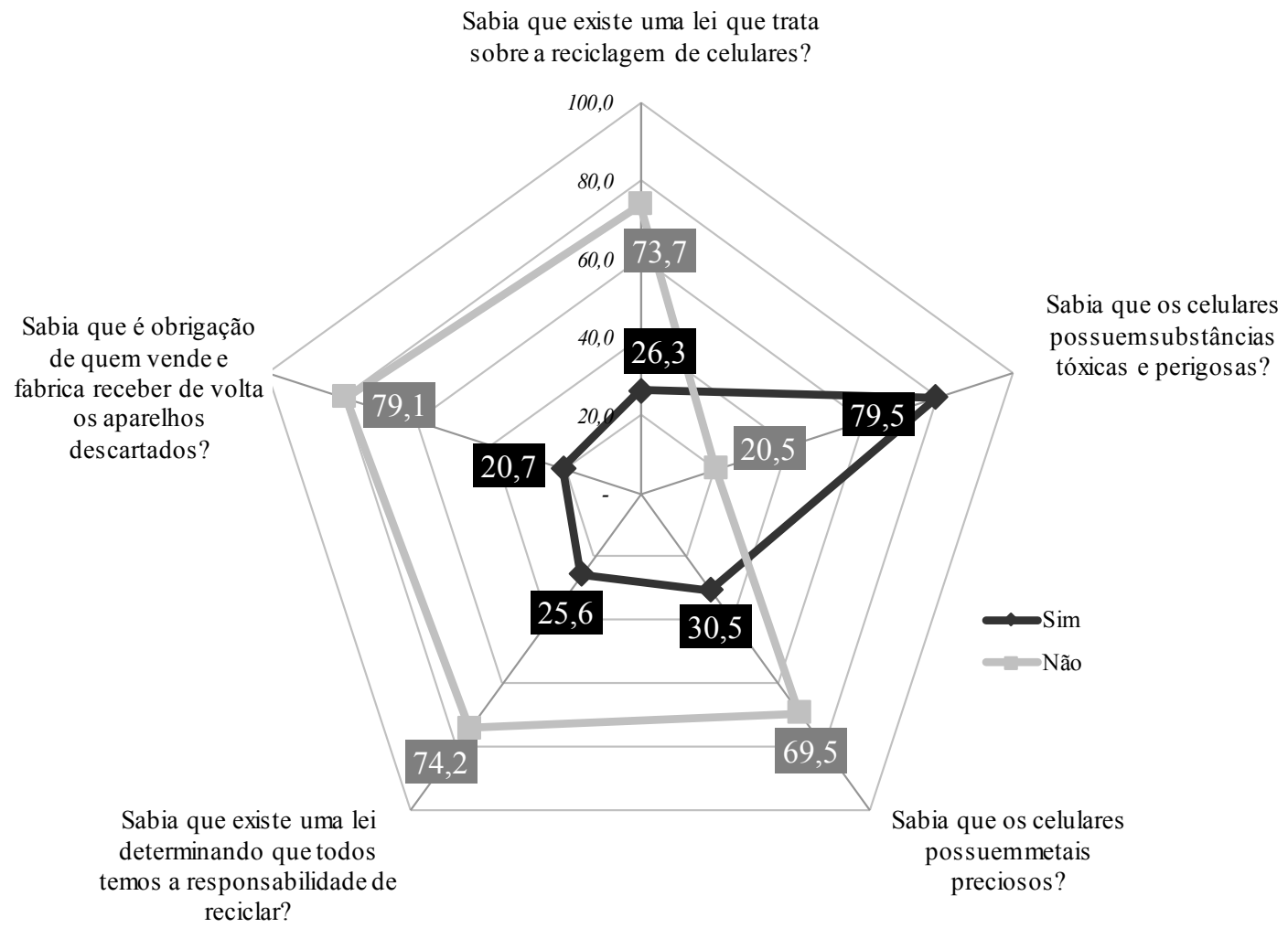

Gráfico 1: Proporção (\%) relativa ao conhecimento da legislação e aos componentes constituintes do aparelho celular

O estudo realizado por Saphores, Ogunseitan e Shapiro (2012) com 2.136 famílias dos Estados Unidos, evidenciou que saber que o lixo eletrônico possui materiais potencialmente perigosos aumenta a disposição dos consumidores em reciclarem, sugerindo que educar as pessoas sobre os perigos da disposição inadequada do lixo eletrônico pode aumentar a sua participação em programas de reciclagem.

\subsection{Disposição em pagar pela reciclagem}

Questionaram-se os participantes acerca de quem deveria ser a responsabilidade pelos custos de coleta e reciclagem de aparelhos celulares descartados, bem como se estavam dispostos a pagar por um percentual desses custos. Conforme pode ser observado na Tabela $6,35,3 \%$ dos participantes responderam que a responsabilidade pelos custos de coleta e reciclagem deve ser do fabricante do aparelho. Outros 105 respondentes $(24,4 \%)$ disseram que a responsabilidade é de todos os envolvidos, índice que, no estudo de Yin, Gao e Xu (2014), foi de apenas 6,1\%.

Tabela 6 - Número e proporção (\%) relativos à opinião sobre quem deve pagar pelos custos de coleta e reciclagem

\begin{tabular}{ccc} 
Quem deve pagar pelos custos de coleta e reciclagem & N.o de respostas & $\%$ de respostas \\
O fabricante & 152 & 35,3 \\
A responsabilidade é de todos & 105 & 24,4 \\
O governo & 103 & 24,0 \\
As operadoras de telefonia & 57 & 13,3 \\
O vendedor & 7 & 1,6 \\
\hline Oconsumidor & 6 & 1,4 \\
\hline Total & 430 & 100,0 \\
\hline
\end{tabular}


Considerando que o consumidor é o beneficiário final dos produtos eletrônicos fabricados, foi questionado aos participantes se concordavam em pagar uma parcela dos custos para reciclagem dos aparelhos celulares descartados. A maioria dos respondentes $(69,1 \%)$ não concorda com o pagamento de qualquer valor, ao passo que $10,7 \%$ concordam em pagar um valor embutido no preço da compra de um novo aparelho. Outros $9,3 \%$ aceitariam pagar uma taxa em separado quando comprassem um novo aparelho e $8,1 \%$ concordariam em pagar uma taxa, para reciclagem dos aparelhos, quando entregassem o celular descartado.

Por fim, foi questionado aos participantes que percentual dos custos para coleta e reciclagem estariam dispostos a pagar caso o consumidor tivesse de contribuir com algum valor. Conforme se verifica no Gráfico 2, a ampla maioria $(87,4 \%)$ aceitaria contribuir com o menor percentual possível - neste caso, entre 0 e $5 \%$ dos custos com coleta e reciclagem.

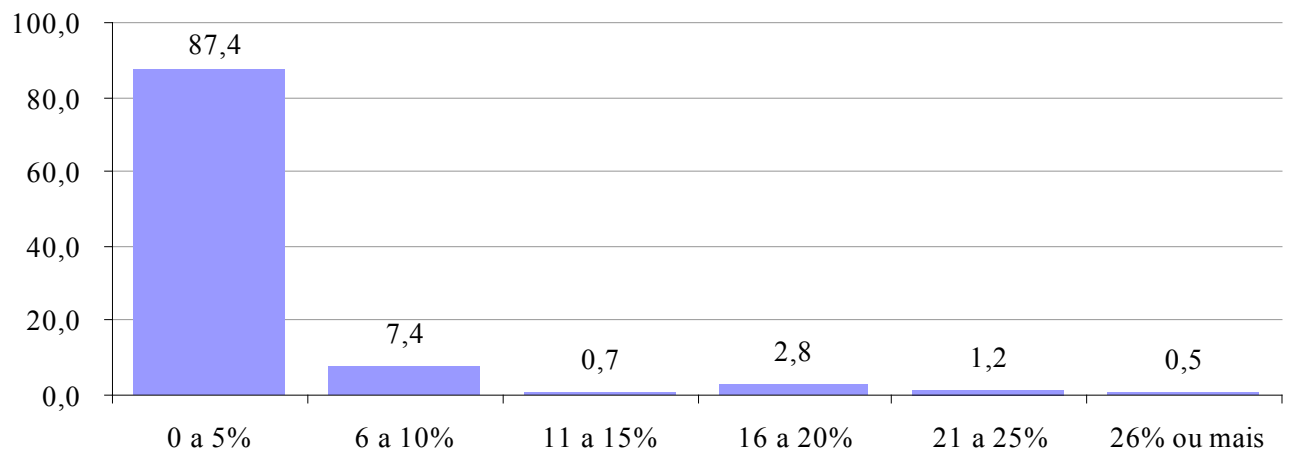

Gráfico 2: Percentual (\%) que aceitaria pagar dos custos de coleta e reciclagem

É difícil encontrar na literatura valores relativos ao processo de coleta de telefones celulares para reciclagem. Conforme descrevem Geyer e Blass (2010), os custos de coleta de aparelhos celulares descartados dependem muito do modelo de negócio e das operações do agente responsável pelo recolhimento. Nesse sentido, empresas que priorizam telefones específicos em final de vida estariam dispostas a pagar um preço elevado para recolher os aparelhos mais rapidamente, enquanto que aquelas empresas com estratégias de coleta menos seletivas teriam como objetivo manter os custos de logística reversa mais baixos.

\section{CONCLUSÕES}

Milhares de telefones celulares são fabricados a cada dia. Na mesma proporção, o descarte de aparelhos rejeitados também vem crescendo. Por tratar-se de um produto eletrônico composto de metais pesados e, por isso, prejudiciais ao meio ambiente e à saúde humana, o tema tem despertado a atenção de autoridades e ambientalistas por todo o mundo. Inserido nesse contexto, o presente artigo teve como objetivo identificar o comportamento dos consumidores da cidade de Santa Maria, Rio Grande do Sul, quanto às atitudes de descarte e à disposição para a reciclagem de aparelhos celulares. De natureza quantitativa, este trabalho foi desenvolvido por meio da aplicação de questionários a 430 consumidores (divididos por nível de escolaridade de acordo com dados da população do município divulgados no último censo realizado pelo IBGE): 34,9\% da amostra não tinha instrução ou tinha ensino fundamental completo, 57,2\% eram homens e 41,4\% tinham 24 anos ou menos no momento da aplicação da pesquisa. 
Como resultado, identificou-se que a maioria dos respondentes $(56,1 \%)$ permanece com seus telefones por no máximo dois anos, sendo o estrago dos aparelhos o principal motivo da substituição (53,5\%), seguido de funções desatualizadas (22,8\%). Para $88,8 \%$ dos participantes, o significado do telefone é unicamente funcional, ou seja, fazer e receber ligações, enviar mensagens e conectar-se à internet.

No que se refere ao destino dado aos telefones descartados, 209 respondentes (48,6\%) guardam os aparelhos em casa e apenas 30 participantes ( $7 \%$ da amostra) devolvem os celulares à operadora ou ao fabricante para serem reciclados. Quando questionados sobre qual o motivo de não destinarem os aparelhos para a reciclagem, 163 entrevistados (40\%) assinalaram que não sabiam onde entregar o telefone, enquanto $127(31,2 \%)$ disseram que preferem doar o aparelho a um parente ou amigo a entregá-lo para ser reciclado e não receber nada em troca. Na opinião de 249 participantes $(57,9 \%)$, as pessoas não reciclam porque há pouca informação sobre o assunto. Outros 104 respondentes atribuem a baixa taxa de reciclagem à falta de consciência ambiental da população. A melhor forma de destinar o aparelho para que seja reciclado, de acordo com 178 entrevistados $(41,4 \%)$, é entregá-lo em lojas do fabricante ou das operadoras. Outros 133 participantes disseram que gostariam de contar com pontos de coleta criados pelo governo.

Quanto ao conhecimento acerca da legislação que versa sobre a reciclagem de produtos eletroeletrônicos e, consequentemente, de aparelhos celulares, a grande maioria dos respondentes a desconhece. Isso ficou evidente quando questionados sobre a existência de uma lei que trata da reciclagem dos aparelhos, sobre a responsabilidade compartilhada dos agentes envolvidos na cadeia dos produtos eletroeletrônicos e sobre a obrigatoriedade dos fabricantes e vendedores a receberem de volta os celulares para serem reciclados. O percentual de respondentes que possuía tal conhecimento foi de, respectivamente, $26,3 \%, 25,6 \%$ e $20,7 \%$. Também era desconhecido para $69,5 \%$ dos entrevistados o fato de que os aparelhos celulares possuem metais preciosos, como ouro, prata e paládio. Esses percentuais foram moderadamente melhores se consideradas apenas as respostas de quem possuía ensino superior completo.

A disposição em pagar pela reciclagem foi verificada por meio de três questões, sendo a primeira acerca de quem deve se responsabilizar pelos custos de coleta e reciclagem dos telefones celulares descartados. Para 152 respondentes (35,3\%), essa responsabilidade deve ser do fabricante do aparelho, enquanto que, para 105 respondentes $(24,4 \%)$, tal responsabilidade deve ser de todos os envolvidos no processo (incluindo a população). Considerando que o consumidor final é o maior beneficiado pela fabricação dos telefones celulares, foi perguntado aos participantes se, por esse motivo, eles concordariam em pagar um percentual do custo com a reciclagem dos aparelhos. 297 pessoas $(69,1 \%)$ disseram não concordar com qualquer pagamento. Por fim, caso o consumidor tivesse de contribuir com algum percentual para a coleta e para a reciclagem de telefones celulares, 376 participantes $(87,4 \%)$ aceitariam contribuir com o mínimo possível, ou seja, entre 0 a $5 \%$ do custo da reciclagem.

Dessa forma, é possível concluir, tendo em vista o objetivo deste estudo, que: a) as atitudes quanto ao descarte dos telefones celulares apresentadas pela amostra pesquisada não contribuem para a correta destinação dos aparelhos, uma vez que sua preferência é pelo armazenamento dos equipamentos em casa, em detrimento de sua devolução à operadora ou ao fabricante para reciclagem; b) existe pouco conhecimento da população sobre os componentes dos celulares e sobre a legislação que trata do descarte de resíduos eletroeletrônicos - o que pode contribuir para a baixa frequência de devolução dos aparelhos em final de vida; e c) não há a disposição em contribuir financeiramente com os custos para a correta reciclagem dos apareIhos descartados, sendo esta responsabilidade, na concepção da maioria dos entrevistados, do fabricante, do governo ou das operadoras de telefonia. 


\section{CONSIDERAÇÕES FINAIS E SUGESTÕES PARA PESQUISAS FUTURAS}

Grandes quantidades de lixo eletrônico são atualmente geradas ao redor do mundo, sem serem, muitas vezes, devidamente tratadas e recicladas. Além disso, pouco se sabe sobre comportamentos, atitudes e disposição das pessoas em pagar pela reciclagem de aparelhos e componentes eletrônicos descartados. O rápido desenvolvimento econômico e social da população, aliado aos avanços tecnológicos percebidos na indústria de telecomunicações, acelerou o ciclo de vida dos produtos, tornando-se necessárias ações que visem diminuir o impacto ambiental provocado pela extração dos recursos minerais e pelo descarte inadequado de seus resíduos na natureza.

Diante disso, este estudo buscou entender e aprofundar o comportamento e as atitudes de uma amostra populacional da cidade de Santa Maria, Rio Grande do Sul, quanto ao descarte de aparelhos celulares após seu consumo. Corroborando com pesquisas realizadas anteriormente, os resultados ora obtidos evidenciam o que descreveu Sally Morgan, já em 2009: centenas de milhões de telefones celulares pós-consumo encontram-se em gavetas e armários em todo o mundo. Conforme aponta Leonard (2010), as operadoras de telefonia costumam oferecer ao cliente aparelhos gratuitos ou a preços módicos quando da assinatura ou da renovação de contratos. Nesse contexto, como recusar a oferta de um modelo mais moderno, com diferentes toques, timbres e cores, e arriscar que o velho telefone apresente defeito no meio do contrato? 0 consumidor não resiste, e lá se vão milhares de celulares ainda em funcionamento para o lixo, ou melhor, para a gaveta.

Outros dados coletados no presente estudo também demonstram o que algumas pesquisas empíricas já haviam apresentado: há pouca informação e conhecimento sobre as leis que tratam do descarte de resíduos eletrônicos, bem como sobre a responsabilidade compartilhada pelo ciclo de vida dos produtos, incluindo-se aí o papel fundamental do consumidor enquanto detentor dos aparelhos em final de vida útil. Para Luther (2010), Nnorom, Ohakwe e Osibanjo (2009) e Saphores, Ogunseitan e Shapiro (2012), o aumento da conscientização do consumidor sobre possíveis problemas advindos da disposição inadequada do lixo eletrônico pode levar a um aumento da reciclagem.

Os consumidores também não estão dispostos a compartilhar os custos envolvidos com a reciclagem dos aparelhos celulares. Fatores econômicos podem influenciar esse posicionamento, mas aspectos culturais também interferem na baixa participação da população na problemática do resíduo eletrônico. Isso ocorre porque a coleta e a destinação do lixo sempre foram vistos como uma responsabilidade dos órgãos públicos, que, por meio de tributos e impostos, arrecadam milhões de reais todos os meses para prestar um serviço que, muitas vezes, não ocorre adequadamente. Esse sentimento de indignação acaba influenciando o comportamento dos consumidores, que se mostram mais resistentes a colaborarem.

O estudo aqui apresentado avança nas discussões sobre o tema e traz, como principais contribuições práticas, algumas constatações importantes, como o fato de que grande parte da população não tem conhecimento de como descartar os aparelhos celulares em seu final de vida útil. Essa descoberta coloca em cheque qualquer possível avanço na cadeia logística da coleta dos aparelhos no Brasil, seja em termos tecnológicos ou de adequação dos processos existentes, já que, sem que o consumidor tenha conhecimento de como proceder e de para onde destinar seus telefones celulares descartados, é pouco provável que haja aumento no percentual de aparelhos reciclados adequadamente. 
Evidenciou-se, ainda, que há um percentual significativo de consumidores que destina o aparelho, após sua utilização, à venda ou à doação - colocando-o novamente em circulação. Tal constatação revela que, embora mais de $50 \%$ dos entrevistados substituam seus celulares, no máximo, a cada dois anos, a vida útil de parte desses aparelhos é maior do que se pressupõe. Esse dado demonstra que algumas informações divulgadas na mídia ou em veículos especializados sobre a vida útil dos aparelhos podem apresentar distorções e devem ser interpretadas com cautela. Nesse quesito, possíveis diferenças podem ser encontradas comparando atitudes de consumidores de países desenvolvidos com atitudes de consumidores de países em desenvolvimento, como o Brasil.

Como principal limitação deste estudo, pode-se citar o instrumento de coleta de dados adotado, que, sendo uma escala não métrica, não permitiu uma análise estatística mais aprofundada. Devido ao limitado tempo disponível para aplicação da pesquisa, também não foi possível realizar teste-piloto, o que poderia contribuir para o refinamento e o ajuste do instrumento utilizado. Uma terceira limitação refere-se ao fato de que os dados coletados dizem respeito ao comportamento, às atitudes e à consciência ambiental de quem respondeu ao questionário. Mesmo que a amostra tenha sido escolhida respeitando o nível percentual de escolaridade da população de Santa Maria, as opiniões coletadas podem não refletir o ponto de vista de toda a população embora existam fortes evidências de que isso tenha ocorrido.

Várias foram as possibilidades de pesquisas futuras identificadas no decorrer deste trabalho. Considerando que a PNRS determina a obrigatoriedade dos fabricantes e comerciantes de produtos eletroeletrônicos de implementarem sistemas de logística reversa, mediante retorno dos produtos após o uso pelo consumidor, seria relevante um estudo que verificasse a adoção dessas práticas junto aos fabricantes e às operadoras de telefonia do país, bem como o grau de divulgação dos programas de recolhimento dos aparelhos eletrônicos, já que foi evidenciada pouca informação sobre o assunto por parte dos respondentes. Em outra linha, pesquisas anteriores demonstraram que o celular, mais do que um item de utilidade para as pessoas, mostra-se um objeto carregado de identidade e simbologia, sendo indicador de prestígio, status e poder. No entanto, os resultados deste estudo revelaram que $88,8 \%$ dos participantes atribuem ao aparelho um significado apenas funcional (fazer e receber ligações, enviar mensagens etc.). Estudos mais aprofundados poderiam ser realizados no intuito de verificar se a aplicação face a face da pesquisa, tal como esta foi realizada, interferiu na resposta dos participantes ou se, realmente, os resultados encontrados refletem o verdadeiro significado do aparelho para as pessoas. Por fim, sugerimos a futuros pesquisadores que continuem estudando o comportamento dos consumidores, com especial atenção aos aspectos que influenciam e inibem sua predisposição à reciclagem, uma vez que os resultados deste estudo demonstraram, assim como os demais trabalhos averiguados, que a população ainda não se conscientizou sobre a importância de destinar adequadamente os resíduos de produtos eletroeletrônicos. 


\section{REFERÊNCIAS}

ASKERZAI, Walied. The negative impact of ICT waste on environment and health. In: UNHELKAR, Bhuvan (Org.). Handbook of research on green ICT: technology, business and social perspectives. v. 1. New York: IGI Global, 2010.

BRASIL, Presidência da República. Casa Civil. Lei no 12.305, de 02 de agosto de 2010. Institui a Política Nacional de Resíduos Sólidos; altera a Lei no 9.605, de 02 de fevereiro de 1998; e dá outras providências. Disponível em: <http:// www.planalto.gov.br/ccivil_03/_ato20072010/2010/lei/l12305.htm>. Acesso em: 23 de junho de 2015.

CHURCHILL, Gilbert A.; IACOBUSSI, Dawn. Marketing research: methodological foundations. 10ed. Mason, Ohio: SouthWestern Thompson Learning, 2009.

CRUZ-SOTELO, Samantha; et al. Hábitos y prácticas de consumo de teléfonos celulares en México y España. Rev. Int. Contam. Ambie., v. 29 (Sup. 3), p. 33-41, 2013.

DIOUF, Boucar; PODE, Ramchandra; OSEI, Rita. Recycling mobile phone batteries for lighting. Renewable Energy, v. 78, p. 509-515, 2015.

DOUGLAS, Mary; ISHERWOOD, Baron. The world of goods. Towards an anthropology of consumption. London: Routledge, 1996.

GEYER, Roland; BLASS, Vered D. The economics of cell phone reuse and recycling. Int J Adv Manuf Technol, v. 47, p. 515-525, 2010.

GIARETTA, Juliana B. Z.; et al. Hábitos relacionados ao descarte pós-consumo de aparelhos e baterias de telefones celulares em uma comunidade acadêmica. Saúde Soc. São Paulo, v. 19, n. 3, p. 678-684, 2010.

GOOSEY, Martin. Introduction and overview. In: HESTER, Ronald E.; HARRISON, Roy M. (Eds.) Electronic waste management. Design, analysis and application. Cambridge: Royal
Society of Chemistry, 2009.

GROSSMAN, Elizabeth. Digital devices, hidden toxics, and human health. Washington: Island Press, 2006.

HAIR, Joseph F.; et al. Análise multivariada de dados. Porto Alegre: Bookman, 2007.

HU, Wen-Chen. Emergent trends in personal, mobile, and handheld computing Technologies. Hershey: IGI Global, 2012.

HUISMAN, Jaco. QWERTY and eco-efficiency analysis on cellular phone treatment in Sweden. The eco-efficiency of the direct smelter route versus mandatory disassembly of printed circuit boards. TU Delft. OCP-Design for Sustainability Program, 2004.

INSTITUTO BRASILEIRO DE GEOGRAFIA E ESTATÍSTICA (IBGE). IBGE Cidades. Disponível em: $<$ http://www.cidades.ibge.gov.br/xtras/perfil.ph p ?lang $=\&$ codmun $=431690 \&$ search=rio-grandedo-sul|santa-maria|infograficos:-informacoescompletas>. Acesso em: 27 jun. 2015.

INSTITUTO BRASILEIRO DE GEOGRAFIA E ESTATÍSTICA (IBGE). Estimativas populacionais para os municípios e para as Unidades da Federação brasileiros em 01.07.2015. Disponível em: <http://www.ibge.gov.br/home/estatistica/ populacao/estimativa2015/estimativa_dou. shtm>. Acesso em: 01 jun. 2016.

INTERNATIONAL TELECOMMUNICATION UNION (ITU). Statistics: Global ICT developments. Disponível em: <http://www. itu.int/en/ITU-D/Statistics/Pages/stat/default. aspx>. Acesso em: 27 jun. 2015.

JANG, Yong-Chul; KIM, Mincheol. Management of used \& end-of-life mobile phones in Korea: a review. Resources, Conservation and Recycling, v. 55, p. 11-19, 2010.

KOGA, Guilherme A.; et al. Comportamento do usuário em relação ao descarte e à reciclagem de aparelhos celulares no estado de São Paulo. Future Studies Research Journal, v. 6, n. 2, p. 03-29, 2014. 
LADOU, Joseph; LOVEGROVE, Sandra. Export of electronics equipment waste. Int J Occup Environ Health, v. 14, p. 1-10, 2008.

LEONARD, Annie. The story of stuff. How our obsession with suffs is trashing the Planet. New York: Simon \& Schuster, 2010.

LI, Bo; et al. Survey on disposal behaviour and awareness of mobile phones in Chinese university students. Procedia Environmental Sciences, v. 16, p. 469-476, 2012.

LUNDGREN, Karin. The global impact of e-waste: addressing the challenge. International Labour Office, Programme on Safety and Health at Work and the Environment (SafeWork), Sectoral Activities Department (SECTOR).Geneva: ILO, 2012.

LUTHER, Linda. Managing electronic waste: issues with exporting e-waste. Washington: Congressional Research Service, 2010.

MACKENZIE, Dorothy; COOPER, Tim; GARNETT, Kenisha. Can durability provide a strong marketing platform? In: COOPER, Tim. (Org.). Longer lasting products: alternatives to the throwaway society. Surrey: Gower Publishing, 2010.

MILOVANTSEVA, Natalia; SAPHORES, JeanDaniel; E-waste bans and U.S. households' preferences for disposing of their e-waste. Journal of Environmental Management, v. 124, p. 8-16, 2013.

MORGAN, Sally. Waste, recycling and reuse. London: White-Thomson Publishing, 2009.

NNOROM, I.C.; OHAKWE, J.; OSIBANJO, O. Survey of willingness of residents to participate in electronic waste recycling in Nigeria - a case study of mobile phone recycling. Journal of Cleaner Production, v. 17, p. 1629-1637, 2009.

ONGONDO, Francis; WILLIAMS, Ian. D. Mobile phone collection, reuse and recycling in the UK. Waste Management, v. 31, p. 1307-1315, 2011.
RENNER, Michael. Moving toward a less consumptive economy. In: The Worldwatch Institute. State of the world. New York: Norton \& Company, 2004.

SAPHORES, Jean-Daniel M.; OGUNSEITAN, Oladele A.; SHAPIRO, Andrew A. Willingness to engage in a pro-environmental behavior: an analysis of e-waste recycling based on a national survey of U.S. households. Resources, Conservation and Recycling, v. 60, p. 49-63, 2012.

SILVEIRA, Geraldo T.R.; CHANG, Shoou-Yuh. Cell phone recycling experiences in the United States and potential recycling options in Brazil. Waste Management, v. 30, p. 2278-2291, 2010.

SOO, Vi K.; DOOLAN, Matthew. Recycling mobile phone impact on life cycle assessment. Procedia CIRP, v. 15, p. 263-271, 2014.

TANSKANEN, Pia. Electronics waste: recycling of mobile phones. In: DAMANHURI, Enri (Org.). Post-consumer waste recycling and optimal production. Rijeka: InTech, 2012.

Teleco. Teleco: inteligência em telecomunicações. 2015. Disponível em: http://www.teleco.com.br. Acesso em: 27 jun. 2015.

WHETTEN, David A. O que constitui uma contribuição teórica? RAE, v. 43, n. 3, p. 69-73, 2003.

XAVIER, Lúcia H.; CARVALHO, Tereza C. A gestão de resíduos eletroeletrônicos no Brasil. CARVALHO, Tereza C.; XAVIER, Lúcia H. (Orgs.). Gestão de resíduos eletroeletrônicos: uma abordagem prática para a sustentabilidade. Rio de Janeiro: Elsevier, 2014.

YIN, Jianfeng; GAO, Yingnan; XU, He. Survey and analysis of consumers' behaviour of waste mobile phone recycling in China. Journal of Cleaner Production, v. 65, p. 517-525, 2014. 